\title{
Social Elites and New Communication Methods/Information Technologies: The Digital Divide
}

\author{
Kostas Rontos \\ Professor at the Department of Sociology at the University of the Aegean \\ University Hill, 81100 Mytilene, Lesvos, Greece \\ k.rontos@soc.aegean.gr \\ Nikos Nagopoulos \\ Associate Professors at the Department of Sociology at the University of the Aegean \\ University Hill, 81100 Mytilene, Lesvos, Greece \\ n.nagopoulos@soc.aegean.gr \\ Tsapala Flora \\ Ph.D Candidate of the Department of Sociology at the University of the Aegean \\ University Hill, 81100 Mytilene, Lesvos, Greece \\ ftsapala@aegean.gr
}

\begin{abstract}
The aim of this article is to examine the directions taken by not only social but transnational inequalities too, in the framework of information society, where trough the internet new means of communication and provision of information that have entered our lives in a determinative way, are developed. The main issue at stake is to define whether the opinion of technological determinism about the effect of new technologies in improving the position of societies through its universal use is verified in practice or if a new elite is created, that with more and better use of the new technologies maintains - if not deepens social inequalities. In relation to the aforementioned and in this particular proposal, apart from the broadened accessibility chances and the increase of the percentage of new technology users in general, especially the distinct character of digital goods and the determining character, both of the way of using them and the quality of these goods in combination with the purpose and the environment of use, is examined.
\end{abstract}

Keywords: Social and geographical inequalities, technological determinism, internet, Social elites, digital divide.

\section{INTRODUCTION}

The most widespread and appropriate research-wise examination of the social consequences regarding the extended and almost massive use of modern technologies that are in favor of the new forms of communication are the correlation of the internet with open democracy and eGovernance. It is indicative that most researches that have been conducted towards that direction attempt to explain and interpret even matters of social or geographical exclusion, social differentiation and marginalization mainly through the preconditions of a massive, free and unhindered access and usage of the new media. In this framework as well as by the possibilities provided for lifting possible restrictions in the usage, the matters of social inequalities are also examined. 
It is thus ascertained that the interests of most existing researches focus on examining the assumption that the same possibility of free access and usage is a necessary and meanwhile sufficient condition of eliminating social or other inequalities. In particular these approaches attempt, in a broader sense, to interpret social inequality through unhindered freedom of access, without penetrating into the quality of usage itself and if through various differentiations, new forms of inequalities emerge.

This particular article initially aims at examining the content that social and geographical inequalities obtain in the framework of information society, where through the internet nowadays new means of technology and provision of information are developed, which decisively effect aspects of every day social life. On the basis thereof, the question is raised, whether internet usage contributes to social cohesion or if in the end to the increase of socialperipheral inequalities?

Furthermore, regarding the more complex question and the inclusion of qualitative parameters, the approach that is attempted here is based on the secondary analysis of large scale researches regarding the restriction or the increase of social and peripheral inequalities between a) different groups of countries across Europe, b) citizens with different socioeconomic characteristics and c) enterprises that present a different size.

\section{THE CONNECTION BETWEEN MASS INTERNET USAGE AND THE INTENSITY OF THE OCCURRENCE OF SOCIAL INEQUALITIES}

According to the questions posed, the initial approach attempts to examine if the opinion of technological determinism regarding the effect of new technology - especially through universal usage- on the improvement of the position of societies is verified in practice or if the emergence of a new elite that with more and better use of the new technologies maintains, if not deepens, the existing social inequalities is apparent.

The first opinion is founded on the argument of the no longer expensive use of the new technologies and the fact that the youth familiarizes with them from a young age. This argument is strengthened by the ascertainment that in an open democracy, in which the freedom of expression is an integral good, internet usage is mainly described by its neutrality (as was typography in the past), that is the non-distinctive or non-privileged and monopoly relation that certain groups can maintain. In short, the possibility of unhindered access itself is a dominant prerequisite of freedom of expression.

In that sense on a political level the internet itself, thus the medium itself, becomes a symbol of opposition to the regime, whereas governments are unable to control the massive use and set restrictions or utilize it exclusively for their own purposes. For example, the attempts to create a black list of addresses and prohibit access to sites with oppositional or insulting, according to the cultural morals of those countries, content, are not unusual.

Nevertheless, in periods of financial crisis, during which even survival and the maintenance of health of a large part of the population cannot be assured, the financial capacity to afford the cost of purchasing and using these new technological means for receiving information is not self-evident. As a consequence, not only the unhindered distribution of information but the existing preconditions for utilization of possibilities to gain access to them are important questions to be researched too. On the other hand, the possibility for the withdrawal of 
inequalities through the restriction of the digital divide incurred by the mass access to the internet is disputed [1].

To this direction, the ease regarding the time of use is one more parameter that defines the equality or inequality produced by using the new technologies. Those who work hard and for many hours, even though they have the financial means, seem not to possess the time to use the internet in a productive way in comparison to economically higher classes.

The issue of the way of using the new technologies remains important as well, given that using them for educational, informative or professional purposes and professional development and the productive use in general requires a higher social and cultural capital as well as a higher educational level and specialization, that in the end are not necessarily obtained by everyone in modern societies. Thus, the lower social classes seem to use the internet and its tools (Facebook, twitter, etc) mainly for recreation or digital social interaction, so the "quality" in use creates a second level of researching inequalities that is connected to the possibility of creating a new social elite, one that has the "Wealth of technologies" and had the ease to use it appropriately and most importantly productively.

\section{NEW FORMS OF INEQUALITIES AND DIFFERENTIATION REGARDING USAGE AND UTILITY}

In relation to the aforementioned and as for the second level of initial questions it is apparent that, apart from the extended opportunities for access and in general increase of the percentage of users of new technologies, the character of digital goods is particularly distinguishable, whereas the factor regarding the way of usage as well as the quality of those goods in combination with the purposes and the usage environment is particularly defining.

In particular, it is interesting a) to be determined if there is a new form of inequalities that are not only located on a level of digital divide, that is accompanied by the possibilities or lack thereof to access the digital goods, but mainly b) to be revealed differences on the quality and the purposes of usage. Regarding those lines of action the relevant argumentation claims that the inequalities are particularly obvious in relation to their quality and the purposes of usage, $[2,3]$ as well as that the characteristics of these new inequalities are mainly detected in the distance that appears between the usage as a necessary utilization of knowledge in an environment of productive or entrepreneurial activity, or even in the formulation and the control of this usage [4] and the one that is restricted, through a relation that does not depend on the broader knowledge, to the simple access skills [5]. The latter, even if they are not utilized in multiple levels of usage, remain outside of the environment of labor performance and utility [6] and also they do not obtain participation in the formulation of a pole of power through the simple utilization of technological means.

Following this argument the characteristics of a new social elite are revealed that does not identify itself as much through the separate ability of using new technologies, but mainly from the continuous and cumulative utility and innovation in a productive and entrepreneurial environment, that increases the inequalities, or highlights new ones [7] as it creates new local and supralocal power networks [4] through the possibilities the utilization of digital goods itself offers towards that direction.

Thus, summarizing these two questions we ascertain that the initial question, that is, if in the framework of information society and the explosive expansion of the number of internet users, 
social but also geographical/peripheral inequalities are reduced, is based on arguments and findings that regard:

- the unhindered and universal use as a possibility and right to access connected with the democratic goods,

- the distinction between traditional and modern technological means of communication,

- the predominance of a technological determinism, thus the position regarding the effect of new technology in the improvement of the life of constantly more citizens, of every social stratum,

- the confirmation of a causal link between the new technology and the overall social wellbeing and development,

- democratic pluralism and broadening democracy, as there is a possibility for free access to common goods,

- the recess of total dominance and fixation on the regime that is achieved through the broader control of power, due to the possibilities offered by the medium itself,

- the dismantling of totalitarian forms of governing and the respective leaderships and the withdrawal of one and only strong political message through the proliferation of multiple messages,

- broadening participation in civic and political representation of a larger number of citizens,

- the incorporation of different opinions and groups in the public consultation, that were silent or left aside.

All of the aforementioned ascertainments, even though they are correctly based on the increase of interactions between the citizens and various poles of power and the fact that interactivity is continuously favored by new techniques, especially when these are offered for mass usage, present an overoptimistic and often formalistic or one-sided or one-factor estimation of the connection between broadening internet usage and the restriction of multiple inequalities.

In this framework, it is not by chance - and particularly in an individualized dimension that is characterized by the absence of social collegialities - that it means the participation in the prospects of electronic governance, which is also called to deal with the crisis of representation in the political system that is being sought. The same meaning is also given to the concept of consultation as it often also derives from the individualized response of citizens, who are familiar with the techniques of using the internet, in the institutional political bodies that raise issues, not as much for a public consultation, but in order for them to be put to the vote; votes, which usually have the character of the opinion poll and are not utilized for consultation regarding the co-formulation of politics.

However, those ascertainments are mainly superficial given that it is doubtful that social and geographical inequalities are dismantled or restricted due to the ascertained broadened internet usage without seeking and analyzing social comparative data that regard socioeconomic characteristics of users, $[8,3]$ the quality of usage and mainly the emphasis on productive processes and carrier prospects, the time of usage and the possibility of utilizing the functions that are constantly being upgraded and that constantly create new working environments and entrepreneurial planning, or even new communication practices with emphasis on the new social collegialities. Against such an ascertainment and similar arguments some particular aspects that can be examined are important, and in particular: 
- the time of usage, thus a parameter that defines the equality or inequality that is produced through the use of new technologies,

- the different possibility of managing time regarding usage of the modern means of technology,

- the distinction between productively available and non-productive time, regarding the utilization of new technologies,

- Internet usage for learning, information, entrepreneurship or for professional purposes and professional development,

As a conclusion, what is being sought is whether the different quality in usage creates conditions to broaden inequalities and create new social elites, which utilize the benefits of the use of the new technologies in the most efficient way.

Including all the aforementioned quality criteria for differentiation regarding the additional hypotheses, the interest of the analysis is shifted further than the broadened chances for access and increase of the percentage of new technologies users and the examination in particular of the distinctive character of the digital goods and the determining factors, that are detected both is their way of usage and in the quality of the goods in combination with the purposes and the environment of usage is attempted.

\section{METHOD OF ANALYSIS AND SOURCES FOR RAISING STATISTIC DATA}

For the examination of the existence of social and peripheral inequalities between a) the various groups of European Countries, b) citizens with different socio-economic characteristics and c) enterprises that present a different size, a secondary analysis of statistic data, which come from surveys in the Member-States of the European Union and published by Eurostat, was conducted.

The time series concerning citizens and households covers the recent period 2005-2013, while for the last year 2013 thematic maps are presented to make similarities and differences among Countries more obvious.

\section{ANALYSIS OF SECONDARY DATA REGARDING THE RESTRICTION OR THE INCREASE OF SOCIAL AND PERIPHERAL INEQUALITIES}

From Table 1 it becomes obvious that in 2005 the citizens of almost all European Countries aged between 16 and 74, have never used the Internet in percentages ranging from 36\% to $82 \%$. The highest percentages of non-usage of the Internet, over $50 \%$, appear in the Southern and Central - Eastern Countries, Spain 50\%, Latvia 51\%, Malta 57\%, Poland 58\%, Hungary 60\%, Lithuania 61\%, Italy 62\%, Czech Republic 63\%, Portugal 63\%, Cyprus 64\%, Greece 73\% and Turkey 82\%, whereas only one country from Western Europe, Ireland (55\%) ranges over $50 \%$. On the contrary, the lowest percentages under 30\% are presented by the Northern and Western Countries of the European Union, Iceland 11\%, Sweden 12\%, Denmark 14\%, Norway 15\%, the Netherlands 18\%, the United Kingdom 28\%, Germany 29\% and Luxemburg 29\%. 
Rontos, K., Nagopoulos, N., \& Flora, T. (2014). Social elites and new communication methods/information technologies: The digital divide. Archives of Business Research, 2(5), 29-46

Table 1: Percentage (\%) of people aged between 16 and 74 that have never used the Internet during the years $2005-2013$

\begin{tabular}{|c|c|c|c|c|c|c|c|c|c|}
\hline & 2005 & 2006 & 2007 & 2008 & 2009 & 2010 & 2011 & 2012 & 2013 \\
\hline EU (28 countries) & $:$ & $:$ & 37 & 33 & 30 & 27 & 24 & 22 & 21 \\
\hline EU ( 27 countries) & 43 & 42 & 37 & 33 & 30 & 27 & 24 & 22 & 20 \\
\hline Belgium & 39 & 34 & 29 & 26 & 20 & 18 & 14 & 15 & 15 \\
\hline Bulgaria & $:$ & 71 & 65 & 57 & 53 & 51 & 46 & 42 & 41 \\
\hline Czech Republic & 63 & 49 & 46 & 33 & 33 & 28 & 24 & 19 & 17 \\
\hline Denmark & 14 & 10 & 12 & 12 & 11 & 9 & 7 & 6 & 4 \\
\hline Germany & 29 & 26 & 23 & 20 & 19 & 17 & 16 & 15 & 13 \\
\hline Estonia & 36 & 34 & 32 & 26 & 26 & 22 & 20 & 19 & 16 \\
\hline Ireland & 55 & 42 & 35 & 32 & 30 & 27 & 21 & 18 & 18 \\
\hline Greece & 73 & 65 & 62 & 56 & 53 & 52 & 45 & 42 & 36 \\
\hline Spain & 50 & 47 & 43 & 38 & 36 & 32 & 29 & 27 & 24 \\
\hline France & : & 46 & 34 & 26 & 25 & 20 & 18 & 15 & 14 \\
\hline Croatia & $:$ & $:$ & 56 & 54 & 47 & 42 & 39 & 35 & 29 \\
\hline Italy & 62 & 59 & 54 & 50 & 45 & 41 & 39 & 37 & 34 \\
\hline Cyprus & 64 & 62 & 56 & 54 & 48 & 45 & 41 & 36 & 32 \\
\hline Latvia & 51 & 45 & 39 & 34 & 31 & 29 & 27 & 24 & 22 \\
\hline Lithuania & 61 & 54 & 49 & 43 & 38 & 35 & 34 & 31 & 29 \\
\hline Luxemburg & 29 & 27 & 20 & 16 & 11 & 8 & 8 & 6 & 5 \\
\hline Hungary & 60 & 52 & 46 & 37 & 36 & 32 & 28 & 26 & 24 \\
\hline Malta & 57 & 58 & 51 & 49 & 40 & 36 & 30 & 29 & 28 \\
\hline The Netherlands & 18 & 16 & 13 & 11 & 10 & 8 & 7 & 6 & 5 \\
\hline Austria & 40 & 34 & 28 & 25 & 25 & 23 & 18 & 17 & 16 \\
\hline Poland & 58 & 52 & 48 & 44 & 39 & 35 & 33 & 32 & 32 \\
\hline Portugal & 63 & 60 & 56 & 54 & 50 & 46 & 41 & 34 & 33 \\
\hline Romania & $:$ & 74 & 69 & 64 & 62 & 57 & 54 & 48 & 42 \\
\hline Slovenia & 48 & 43 & 39 & 40 & 33 & 28 & 29 & 28 & 23 \\
\hline Slovakia & 42 & 41 & 35 & 25 & 22 & 17 & 20 & 18 & 15 \\
\hline Finland & 23 & 18 & 17 & 13 & 15 & 11 & 9 & 7 & 6 \\
\hline Sweden & 12 & 10 & 15 & 9 & 7 & 7 & 5 & 5 & 4 \\
\hline United Kingdom & 28 & 29 & 22 & 19 & 15 & 13 & 11 & 10 & 8 \\
\hline Iceland & 11 & 9 & 8 & 8 & 6 & 5 & 4 & 3 & 3 \\
\hline Norway & 15 & 17 & 11 & 8 & 6 & 5 & 5 & 4 & 3 \\
\hline $\begin{array}{l}\text { Former Yugoslav } \\
\text { Republic }\end{array}$ & $:$ & 69 & $:$ & 51 & 47 & 44 & : & $:$ & $:$ \\
\hline Serbia & : & & 65 & : & 56 & : & : & : & $:$ \\
\hline Turkey & 82 & & 70 & 64 & 62 & 58 & : & : & 51 \\
\hline
\end{tabular}

Source: Eurostat,

http://epp.eurostat.ec.europa.eu/tgm/table.do?tab=table\&init=1\&plugin=1\&language=en\&pcode=tin00093

Gradually and until today (2013) these percentages are decreasing spectacularly in every country. However, the Southern and Central - Eastern Countries of the European Union continue, until 2013, to present the highest percentages of people aged 16 to 74 who have never used the Internet [Bulgaria (41\%), Romania (42\%), Greece (36\%), Italy (34\%), Cyprus 
(32\%), Portugal (33\%), Turkey (51\%), Poland (32\%), Spain (24\%), Croatia (29\%), Latvia (22\%), Lithuania (29\%), Hungary (24\%), Malta (28\%), Slovenia (23\%)]. On the contrary, the Northern - Western Countries keep on reducing the percentages of non-usage of the Internet and in 2013 some of them present a single-digit percentage [Iceland (3\%), Norway (3\%), Sweden (4\%), Denmark (4\%), the Netherlands (5\%), Luxemburg (5\%), Finland (6\%), the United Kingdom (8\%), France (14\%), Belgium (15\%)] (Map 1).

Map 1: Percentage (\%) of people aged 16 to 74 years that have never used the Internet in 2013

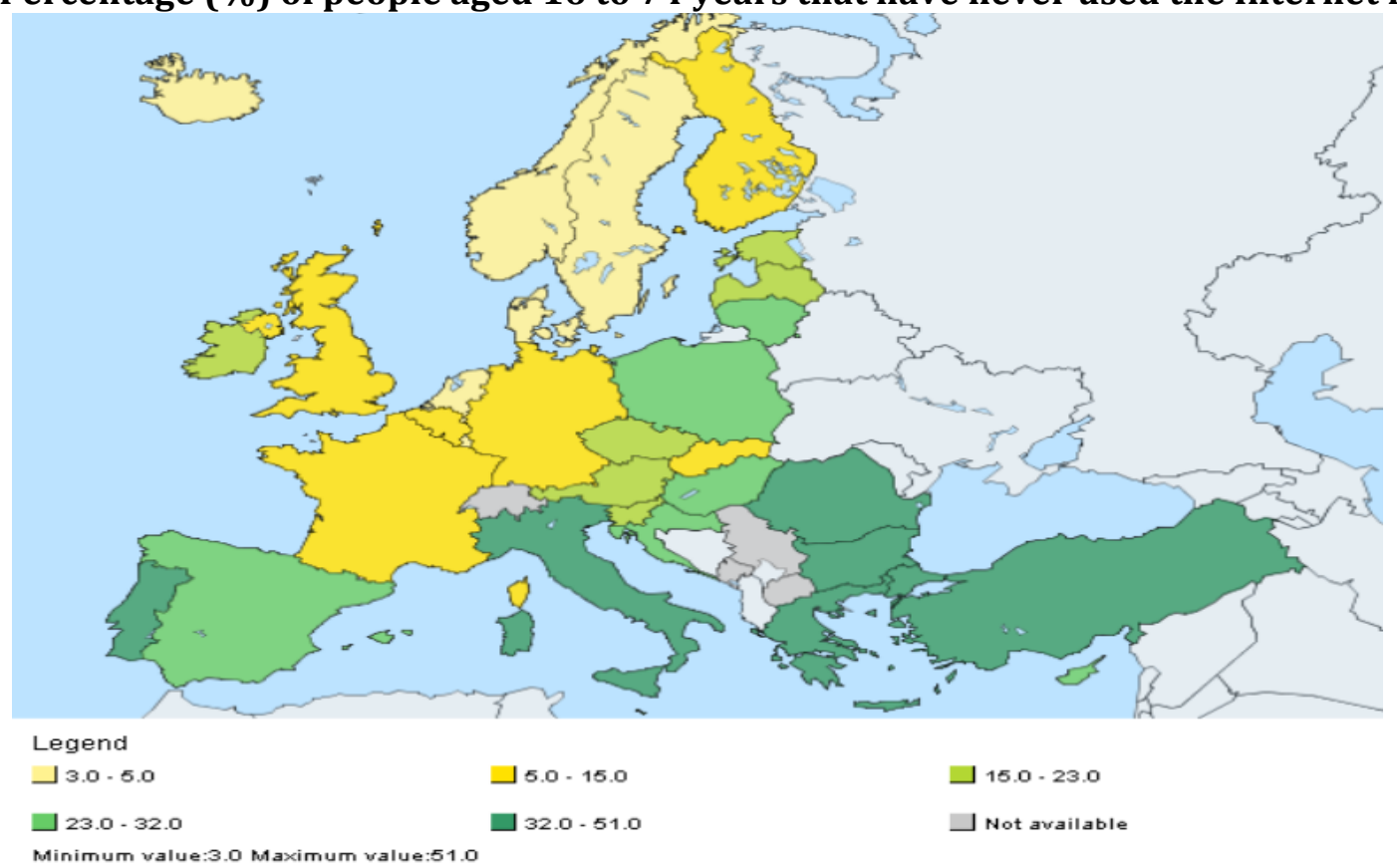

Source: Eurostat,

http://epp.eurostat.ec.europa.eu/tgm/table.do?tab=table\&init=1\&plugin=1\&language=en\&pcode=tin00093

Regarding the level of Internet access of households, it is obvious from Table 2 that even since the first years of the analysis the Northern-Western Countries present the highest percentages of Internet access, over 50\% [Belgium (50\%), Finland (54\%), United Kingdom (60\%), Norway (64\%), Luxemburg (65\%), Sweden (73\%), Denmark (75\%), the Netherlands (78\%) and Iceland (84\%)]. Following a constant increase, regarding the level of Internet access of households in 2013, all European Union countries range over 50\% (Map 2). As a matter of fact, some of them such as Denmark, Luxemburg, the Netherlands, Norway and Iceland tend to approach $100 \%$. 
Table 2: Level of Internet access of Households during the years 2005 - 2013 (percentages \%)

\begin{tabular}{|l|l|l|l|l|l|l|l|l|l|}
\hline & $\mathbf{2 0 0 5}$ & $\mathbf{2 0 0 6}$ & $\mathbf{2 0 0 7}$ & $\mathbf{2 0 0 8}$ & $\mathbf{2 0 0 9}$ & $\mathbf{2 0 1 0}$ & $\mathbf{2 0 1 1}$ & $\mathbf{2 0 1 2}$ & $\mathbf{2 0 1 3}$ \\
\hline EU (28 countries) & $:$ & $:$ & 55 & 60 & 66 & 70 & 73 & 76 & 79 \\
\hline EU (27 countries) & 48 & 49 & 55 & 60 & 66 & 70 & 73 & 76 & 79 \\
\hline Belgium & 50 & 54 & 60 & 64 & 67 & 73 & 77 & 78 & 80 \\
\hline Bulgaria & $:$ & 17 & 19 & 25 & 30 & 33 & 45 & 51 & 54 \\
\hline Czech Republic & 19 & 29 & 35 & 46 & 54 & 61 & 67 & 65 & 73 \\
\hline Denmark & 75 & 79 & 78 & 82 & 83 & 86 & 90 & 92 & 93 \\
\hline Germany & 62 & 67 & 71 & 75 & 79 & 82 & 83 & 85 & 88 \\
\hline Estonia & 39 & 46 & 53 & 58 & 63 & 68 & 71 & 75 & 80 \\
\hline Ireland & 47 & 50 & 57 & 63 & 67 & 72 & 78 & 81 & 82 \\
\hline Greece & 22 & 23 & 25 & 31 & 38 & 46 & 50 & 54 & 56 \\
\hline Spain & 36 & 39 & 45 & 51 & 54 & 59 & 64 & 68 & 70 \\
\hline France & $:$ & 41 & 55 & 62 & 69 & 74 & 76 & 80 & 82 \\
\hline Croatia & $:$ & $:$ & 41 & 45 & 50 & 56 & 61 & 66 & 65 \\
\hline Italy & 39 & 40 & 43 & 47 & 53 & 59 & 62 & 63 & 69 \\
\hline Cyprus & 32 & 37 & 39 & 43 & 53 & 54 & 57 & 62 & 65 \\
\hline Latvia & 31 & 42 & 51 & 53 & 58 & 60 & 64 & 69 & 72 \\
\hline Lithuania & 16 & 35 & 44 & 51 & 60 & 61 & 60 & 60 & 65 \\
\hline Luxemburg & 65 & 70 & 75 & 80 & 87 & 90 & 91 & 93 & 94 \\
\hline Hungary & 22 & 32 & 38 & 48 & 55 & 60 & 65 & 69 & 71 \\
\hline Malta & 41 & 53 & 54 & 59 & 64 & 70 & 75 & 77 & 79 \\
\hline The Netherlands & 78 & 80 & 83 & 86 & 90 & 91 & 94 & 94 & 95 \\
\hline Austria & 47 & 52 & 60 & 69 & 70 & 73 & 75 & 79 & 81 \\
\hline Poland & 30 & 36 & 41 & 48 & 59 & 63 & 67 & 70 & 72 \\
\hline Portugal & 31 & 35 & 40 & 46 & 48 & 54 & 58 & 61 & 62 \\
\hline Romania & $:$ & 14 & 22 & 30 & 38 & 42 & 47 & 54 & 58 \\
\hline Slovenia & 48 & 54 & 58 & 59 & 64 & 68 & 73 & 74 & 76 \\
\hline Slovakia & 23 & 27 & 46 & 58 & 62 & 67 & 71 & 75 & 78 \\
\hline Finland & 54 & 65 & 69 & 72 & 78 & 81 & 84 & 87 & 89 \\
\hline Sweden & 73 & 77 & 79 & 84 & 86 & 88 & 91 & 92 & 93 \\
\hline United Kingdom & 60 & 63 & 67 & 71 & 77 & 80 & 83 & 87 & 88 \\
\hline Iceland & 84 & 83 & 84 & 88 & 90 & 92 & 93 & 95 & 96 \\
\hline Norway & 64 & 69 & 78 & 84 & 86 & 90 & 92 & 93 & 94 \\
\hline Former Yugoslav & & & & & & & & & \\
Republic & $:$ & 14 & $:$ & 29 & 42 & 46 & $:$ & $:$ & $:$ \\
\hline Serbia & $:$ & $:$ & 26 & $:$ & 37 & $:$ & $:$ & $:$ & $:$ \\
\hline Turkey & 8 & $:$ & 20 & 25 & 30 & 42 & $:$ & $:$ & 49 \\
\hline Saurlen|l| \\
\hline
\end{tabular}

Source: Eurostat,

http://epp.eurostat.ec.europa.eu/tgm/table.do?tab=table\&init=1\&plugin=0\&language=en\&pcode=tin00134 


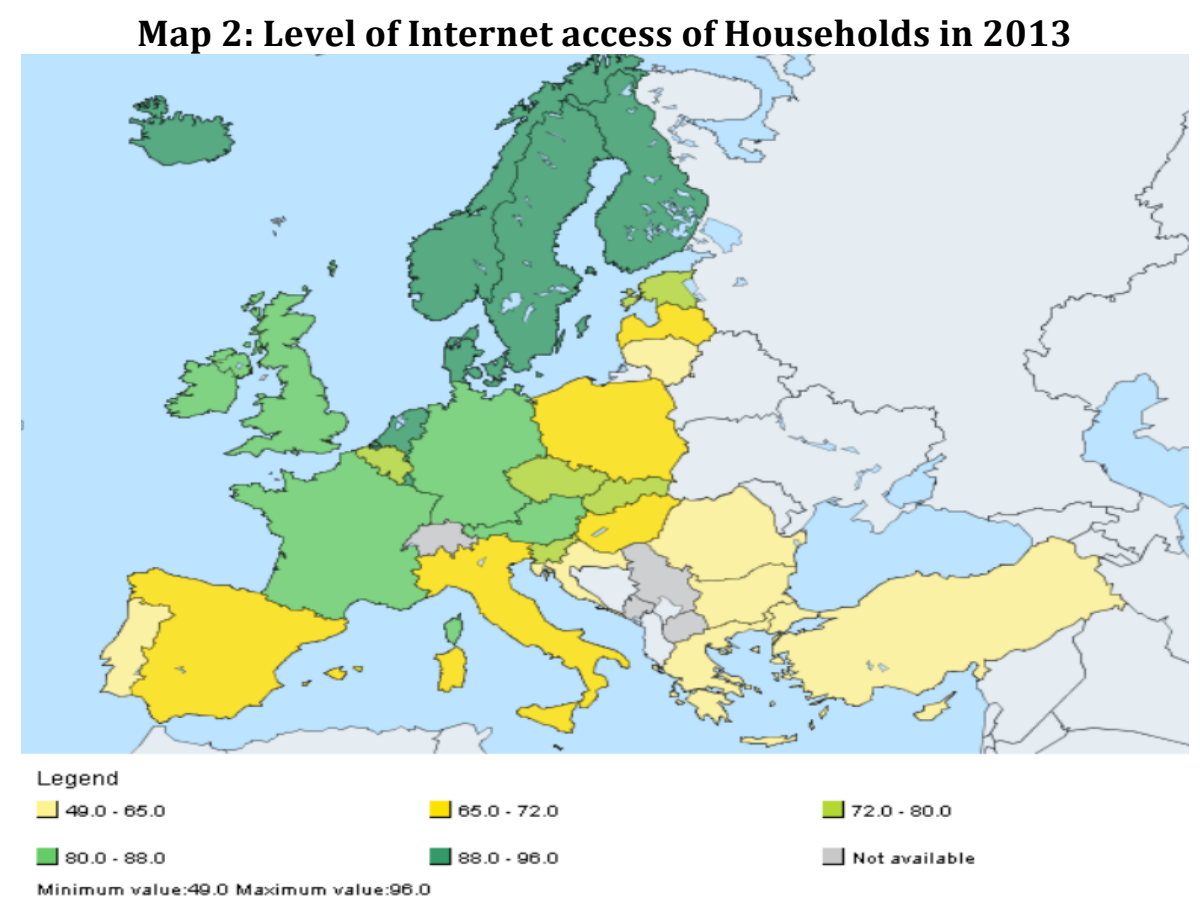

Source: Eurostat,

http://epp.eurostat.ec.europa.eu/tgm/table.do?tab=table\&init=1\&plugin=0\&language=en\&pcode=tin00134

As has already been mentioned, an important factor to define social cohesion or social and peripheral inequalities, that can be brought upon by Internet usage is the way it is being used (learning, information, entrepreneurship or simple usage). Through Table 3 it is obvious that the highest percentage of people, who use the Internet in order to search for information aiming at learning in 2007, appears in the Northern - Western Countries [Finland (30\%), France (41\%), Iceland (42\%), Norway (46\%), Luxemburg (47\%) and Denmark (53\%)]. In 2010 the usage aiming at learning increases in all of Europe in comparison to 2007 and the countries with a high percentage in 2007 relatively slow down their pace, in a way that in some cases a decrease of the percentage to be appeared in comparison to 2009. On the contrary, several countries with lower percentages in 2007 accelerated this usage significantly. Greece, as a characteristic example, from $5 \%$ in 2007 , approaches $24 \%$ in 2010 . In general, the image regarding this characteristic is mixed in Europe with Bulgaria maintaining the Internet usage for learning only at $5 \%$ and Spain surpassing $70 \%$ of its population. 
Table 3: Percentage (\%) of people using the Internet for searching for information aiming at learning (2007 - 2010)

\begin{tabular}{|c|c|c|c|c|}
\hline & 2007 & 2008 & 2009 & 2010 \\
\hline EU (28 countries) & 23 & 27 & 32 & 32 \\
\hline EU (27 countries) & 23 & 27 & 32 & 32 \\
\hline Belgium & 17 & 20 & 27 & 31 \\
\hline Bulgaria & 2 & 5 & 4 & 5 \\
\hline Czech Republic & 17 & 25 & 26 & 21 \\
\hline Denmark & 53 & 47 & 50 & 56 \\
\hline Germany & 27 & 28 & 31 & 29 \\
\hline Estonia & $:$ & 22 & 24 & 26 \\
\hline Ireland & 16 & 21 & 30 & 35 \\
\hline Greece & 5 & 22 & 23 & 24 \\
\hline Spain & 19 & 25 & 29 & 29 \\
\hline France & 41 & 47 & 53 & 47 \\
\hline Croatia & 13 & 17 & 18 & 21 \\
\hline Italy & 21 & 24 & 32 & 35 \\
\hline Cyprus & 21 & 17 & 23 & 22 \\
\hline Latvia & 5 & 13 & 34 & 39 \\
\hline Lithuania & 20 & 20 & 22 & 20 \\
\hline Luxemburg & 47 & 50 & 59 & 65 \\
\hline Hungary & 19 & 22 & 29 & 30 \\
\hline Malta & 21 & 23 & 34 & 38 \\
\hline The Netherlands & 14 & 15 & 17 & 19 \\
\hline Austria & 9 & 12 & 24 & 27 \\
\hline Poland & 19 & 28 & 31 & 33 \\
\hline Portugal & 26 & 33 & 39 & 39 \\
\hline Romania & 8 & 11 & 15 & 17 \\
\hline Slovenia & 24 & 31 & 29 & 42 \\
\hline Slovakia & 3 & 14 & 15 & 21 \\
\hline Finland & 30 & 31 & 66 & 67 \\
\hline Sweden & 27 & 33 & 37 & 44 \\
\hline United Kingdom & 24 & 25 & 31 & 29 \\
\hline Iceland & 42 & 65 & 68 & 71 \\
\hline Norway & 46 & 52 & 51 & 57 \\
\hline $\begin{array}{l}\text { Former Yugoslav Republic of } \\
\text { Macedonia }\end{array}$ & $:$ & 14 & 15 & 11 \\
\hline Serbia & 1 & $:$ & 10 & $:$ \\
\hline Turkey & 10 & 10 & 11 & 14 \\
\hline
\end{tabular}

Source: Eurostat, http://epp.eurostat.ec.europa.eu/tgm/table.do?tab=table\&init=1\&plugin=1\& language $=$ en $\&$ pcode $=$ tin 00104 
Map 3: People who use the Internet for searching for information aiming at learning in 2010

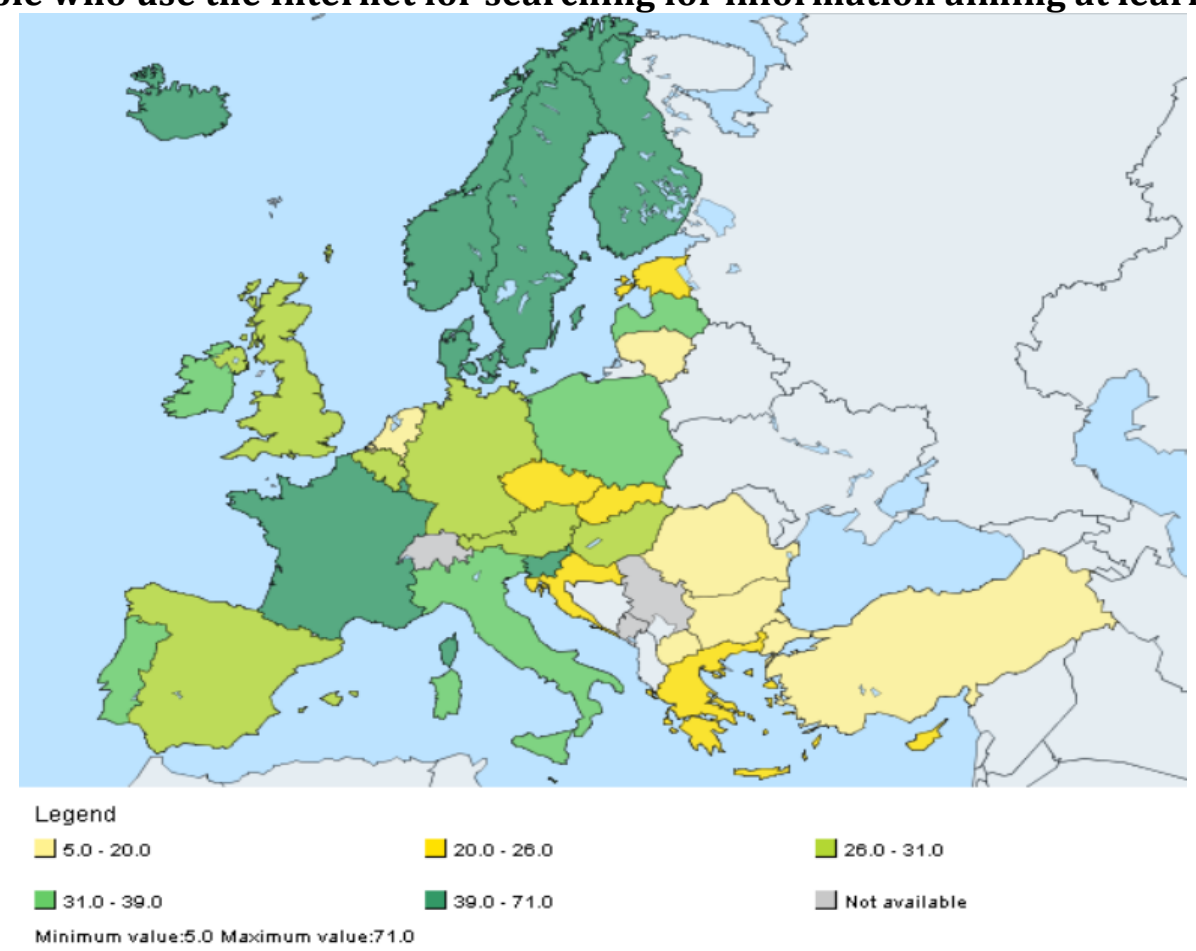

Source: Eurostat,

http://epp.eurostat.ec.europa.eu/tgm/table.do?tab=table\&init=1\&plugin=1\&language=en\&pcode=tin00104

Map 3 also makes obvious the gap between, this time, Western and Eastern Countries in Europe.

One more important factor to examine is the level of personal Internet usage skills for people aged 16 to 74 years. In particular, the 6 usage skills that have been taken into account in the production of the data of table 4 and map 4 are the following: the usage of search engines, sending e-mails with attached files, sending messages in chatrooms, newsgroups or any online discussion forum, Internet usage for phone calls and peer-to-peer file sharing for sharing movies, music

(Eurostat,http://epp.eurostat.ec.europa.eu/tgm/table.do?tab=table\&init=1\&plugin=1\&language=en \&pcode=tsdsc470 ).

Through Table 4 it is obvious that the skills of people of every country for all the years of researching range in low levels under $50 \%$ even in 2013. The particular data refer to people who have achieve at least 1 of the above 6 skills regarding the Internet. It is characteristic that these skills are not extended in more people in Europe, during the 2005-2013 period of time, as a matter of fact in some countries and developed internet-wise as well (Sweden, Denmark etc) they are becoming dramatically less. 
Rontos, K., Nagopoulos, N., \& Flora, T. (2014). Social elites and new communication methods/information technologies: The digital divide. Archives of Business Research, 2(5), 29-46

Table 4: Percentage \% of people with skills in the use of the Internet aged between 16 and 74 during the years $2005-2013$

\begin{tabular}{|c|c|c|c|c|c|c|}
\hline & 2005 & 2006 & 2007 & 2010 & 2011 & 2013 \\
\hline EU ( 28 countries) & $:$ & $:$ & 29 & 31 & 30 & 30 \\
\hline EU ( 27 countries) & 31 & 30 & 29 & 31 & 30 & 30 \\
\hline Belgium & $:$ & 39 & 40 & 39 & 34 & 29 \\
\hline Bulgaria & : & 10 & 13 & 21 & 19 & 22 \\
\hline Czech Republic & : & 30 & 25 & 31 & 28 & 32 \\
\hline Denmark & 47 & 40 & 37 & 36 & 29 & 23 \\
\hline Germany & 41 & 41 & 41 & 41 & 42 & 46 \\
\hline Estonia & 18 & 17 & 20 & 23 & 19 & 24 \\
\hline Ireland & 37 & 42 & 42 & 36 & 36 & 35 \\
\hline Greece & 20 & 23 & 22 & 25 & 20 & 21 \\
\hline Spain & $:$ & 27 & 23 & 30 & 28 & 27 \\
\hline France & : & $:$ & 25 & 29 & 31 & 34 \\
\hline Croatia & $:$ & : & 15 & 25 & 17 & 29 \\
\hline Italy & 14 & 14 & 15 & 20 & 21 & 19 \\
\hline Cyprus & 20 & 20 & 25 & 24 & 20 & 22 \\
\hline Latvia & 27 & 29 & 22 & 22 & 12 & 23 \\
\hline Lithuania & 20 & 20 & 18 & 17 & 13 & 12 \\
\hline Luxemburg & 34 & 31 & 28 & 37 & 30 & 32 \\
\hline Hungary & 19 & 23 & 22 & 24 & 22 & 20 \\
\hline Malta & 28 & 22 & 22 & 24 & 19 & 26 \\
\hline The Netherlands & 49 & 44 & 39 & 36 & 34 & 36 \\
\hline Austria & 38 & 36 & 38 & 38 & 35 & 35 \\
\hline Poland & 22 & 22 & 24 & 28 & 29 & 23 \\
\hline Portugal & 20 & 22 & 16 & 15 & 20 & 21 \\
\hline Romania & $:$ & 14 & 16 & 25 & 20 & 29 \\
\hline Slovenia & 30 & 27 & 25 & 30 & 23 & 28 \\
\hline Slovakia & 39 & 34 & 34 & 29 & 27 & 26 \\
\hline Finland & 37 & 39 & 39 & 48 & 29 & 27 \\
\hline Sweden & 52 & 48 & 45 & 38 & 30 & 25 \\
\hline United Kingdom & $:$ & 38 & 41 & 38 & 35 & 31 \\
\hline Iceland & 37 & 35 & 31 & 25 & 20 & 18 \\
\hline Norway & 39 & 35 & 38 & 36 & 30 & 37 \\
\hline Switzerland & $:$ & $:$ & $:$ & $:$ & $:$ & $:$ \\
\hline $\begin{array}{l}\text { Former } \\
\text { Yugoslav Republic of } \\
\text { Macedonia }\end{array}$ & : & 21 & $:$ & 21 & : & : \\
\hline Serbia & $:$ & $:$ & 20 & $:$ & $:$ & $:$ \\
\hline Turkey & $:$ & : & 27 & 22 & : & 27 \\
\hline
\end{tabular}

Source: Eurostat,

http://epp.eurostat.ec.europa.eu/tgm/table.do?tab=table\&init=1\&plugin=1\&language=en\&pcode=tsdsc470

Through table 4 it is obvious that people who present higher skills are the citizens of Germany (46\%), Norway (37\%), the Netherlands (36\%), Ireland (35\%), Austria (35\%), France (34\%), the Czech Republic (32\%) and Luxemburg (32\%). These are followed, with lower percentages, by the citizens of the United Kingdom (31\%), Romania (29\%), Croatia (29\%), Belgium (29\%), Slovenia (28\%), Turkey (27\%), Finland (27\%) and Spain (27\%). All the other countries follow with percentages under $26 \%$ whereas Italy (19\%), Iceland (19\%) and Lithuania (15\%) range under $20 \%$. 
Table 4: Percentage \% of people with skills in Internet usage aged between 16 and 74 during the year 2013

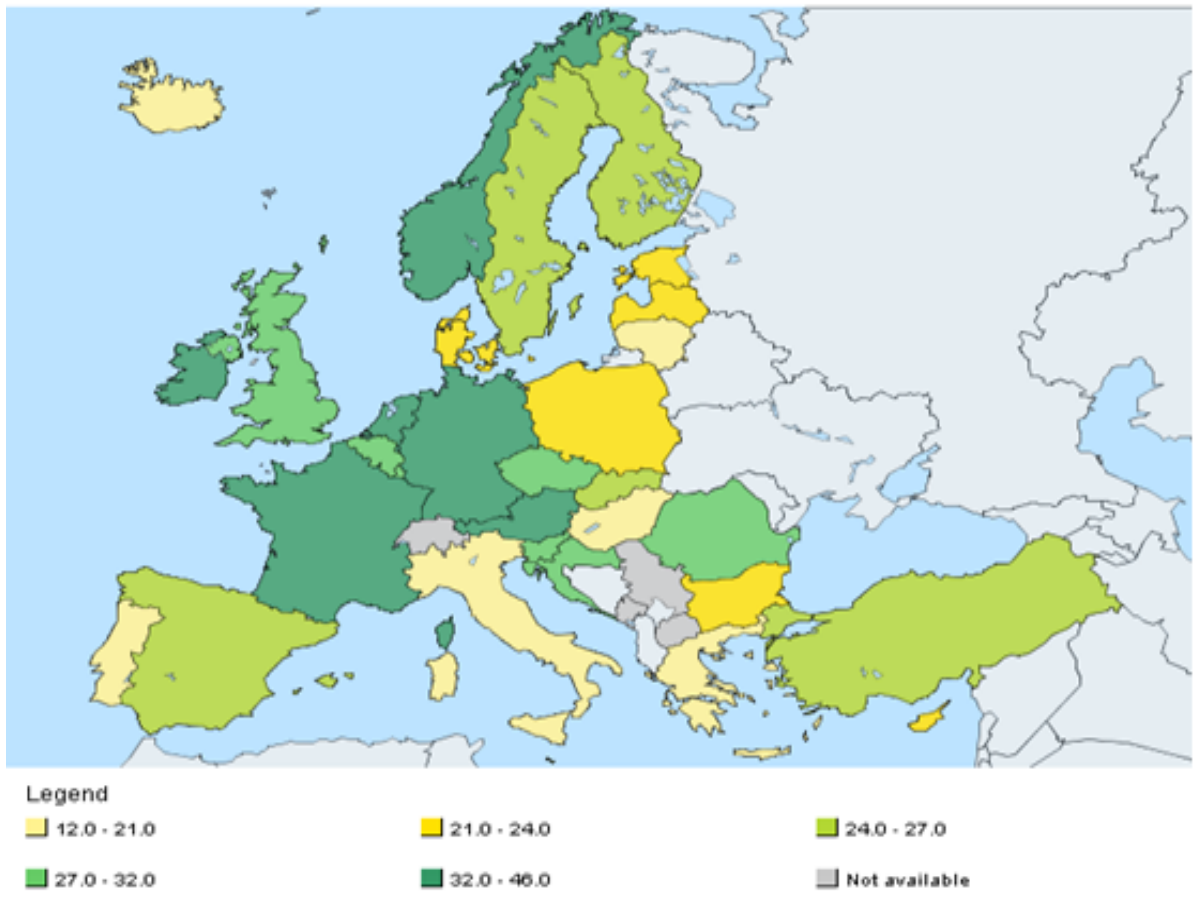

Source: Eurostat,

http://epp.eurostat.ec.europa.eu/tgm/table.do?tab=table\&init=1\&plugin=1\&language=en \&pcode=tsdsc470

The regional pattern of differences between western-eastern countries is appeared again, according the map 4.

At this point it is important to present the utilization rate of the Internet according to the level of education. It is obvious that in the European Union as a whole as well as in the individual countries, the percentage of people who use the internet is very high among the people with a higher level of education, whereas at a lower level of education the percentage of using the internet decreases. In the European Union of 28 member states $95 \%$ of the people with a high level of education use the Internet, at a middle level of education this percentage decreases to $80 \%$ and at a lower level at $52 \%$. The same tendency is presented in the individual countries of table 5, too. It is also characteristic that between the countries, regarding every level of education, the participation is higher in countries such as Denmark, Sweden and the Netherlands compared with Greece, Bulgaria and Romania. It is interesting that in the first countries the percentage for people of a higher level of education is up to $100 \%$. On the contrary, in the last countries (of the South) the amount of people with low level of education using the Internet is extremely low (21-35\%).

In particular, in Greece $25 \%$ of the people with low level of education, $70 \%$ of the people with a medium level of education and $91 \%$ of people with a high level of education use the Internet. Respectively, in Italy, 35\% of the people with low level of education, $76 \%$ of the people with a middle level of education and $87 \%$ of the people with a high level of education use the Internet. In Spain, the respective percentages are 49\%, 86\% and 95\% and in Bulgaria 21\%, 54\% and $88 \%$. It is remarkable that the percentage of people who used the Internet during the last trimester of 2013 in the Netherlands, Denmark and Sweden are closer among all three levels of education (over $80 \%$ ). 
Table 5: Percentage \% of people who used the Internet the last trimester according to their level of education in selected EU Countries, 2013

\begin{tabular}{|l|c|c|c|}
\hline \multirow{2}{*}{ COUNTRY } & \multicolumn{3}{|c|}{ LEVEL OF EDUCATION } \\
\cline { 2 - 4 } & LOW $^{*}$ & MIDDLE** & HIGH*** $^{*}$ \\
\hline E.U.-28 & 52 & 80 & 95 \\
\hline Greece & 25 & 70 & 91 \\
\hline Italy & 35 & 76 & 87 \\
\hline Spain & 49 & 86 & 95 \\
\hline Netherlands & 83 & 97 & 99 \\
\hline Denmark & 91 & 96 & 99 \\
\hline Sweden & 82 & 96 & 99 \\
\hline Bulgaria & 21 & 54 & 88 \\
\hline Romania & 23 & 53 & 94 \\
\hline
\end{tabular}

Source: Eurostat, http://epp.eurostat.ec.europa.eu

*Low level: no official education or primary education or lower secondary education (junior high school)

** Middle level: Upper secondary education (senior high school) or post-secondary (non-tertiary)

*** High level: higher education

At this point it is important to present the utilization ratio of the Internet according to income. It is obvious that in the European Union as a whole as well as in the individual countries, the percentage of people who use the internet is very high among the people with a higher income, whereas for people with a lower income the percentage of using the internet decreases. In the European Union of 28 member states $96 \%$ of the people with a high income use the Internet, at a middle level of income this percentage decreases to $85 \%$ and at a very low level at $60 \%$. The same tendency is also presented in the individual countries of table 6. It is also characteristic that between the countries themselves regarding every level of income the participation is higher in countries such as Denmark, Sweden and Belgium compared with Bulgaria, Lithuania, Italy, Hungary, Poland and Greece. It is interesting that in the former countries the percentage for people of a high level of income is up to $100 \%$. On the contrary, in the latter countries (in the South, Center- Eastern) the amount of people with very low income using the Internet is extremely low $(17-42 \%)$.

Table 6: People who used the Internet during the last trimester according to their income level $\%$ in E.U. countries 2013

\begin{tabular}{|l|c|c|c|c|}
\hline \multirow{2}{*}{ LAND } & \multicolumn{4}{|c|}{ IN COME } \\
\cline { 2 - 5 } Belgium & VERY LOW & LOW & MIDDLE & HIGH \\
\hline Denmark & 60 & 71 & 85 & 96 \\
\hline Lithuania & 83 & 93 & 97 & 99 \\
\hline Hungary & 31 & 50 & 75 & 93 \\
\hline Poland & 37 & 55 & 76 & 94 \\
\hline Sweden & 41 & 56 & 68 & 78 \\
\hline Bulgaria & 83 & 91 & 96 & 99 \\
\hline Greece & 17 & 33 & 63 & 77 \\
\hline Italy & 42 & 62 & 84 & 74 \\
\hline
\end{tabular}

Source: Eurostat, http://epp.eurostat.ec.europa.eu

Finally, according to Table 7, the deviation of enterprises between countries is smaller, that is enterprises as a whole use the Internet on a larger scale in comparison with individuals. Nevertheless, small enterprises present, even the slightest, smaller percentages of Internet access. This also constitutes a differentiation in the enterprise's possibilities to develop in favor of the larger ones, which are generally presumed to be more sustainable. 
Table 7: Internet access level of enterprises during 2013 (Percentage \%)

\begin{tabular}{|c|c|c|c|c|c|}
\hline & $\begin{array}{c}\text { Small } \\
\text { enterprises* }\end{array}$ & $\begin{array}{c}\text { Large } \\
\text { enterprises }\end{array}$ & & $\begin{array}{c}\text { Small } \\
\text { enterprises* }\end{array}$ & $\begin{array}{c}\text { Large } \\
\text { enterprises }\end{array}$ \\
\hline EU ( 28 countries) & 96 & 100 & Hungary & 87 & 98 \\
\hline EU ( 27 countries) & 96 & 100 & Malta & 94 & 98 \\
\hline Belgium & 96 & 99 & $\begin{array}{l}\text { The } \\
\text { Netherlands }\end{array}$ & 100 & 100 \\
\hline Bulgaria & 87 & 99 & Austria & 97 & 100 \\
\hline Czech Republic & 96 & 100 & Poland & 92 & 100 \\
\hline Denmark & 99 & 100 & Portugal & 95 & 100 \\
\hline Germany & 98 & 100 & Romania & 82 & 98 \\
\hline Estonia & 96 & 100 & Slovenia & 97 & 100 \\
\hline Ireland & 94 & 99 & Slovakia & 98 & 99 \\
\hline Greece & 86 & 100 & Finland & 100 & 100 \\
\hline Spain & 96 & 100 & Sweden & 97 & 99 \\
\hline France & 99 & 100 & $\begin{array}{l}\text { United } \\
\text { Kingdom }\end{array}$ & 95 & 99 \\
\hline Croatia & 97 & 99 & Iceland & 98 & 100 \\
\hline Italy & 97 & 100 & Norway & 97 & 99 \\
\hline Cyprus & 92 & 100 & $\begin{array}{l}\text { Former } \\
\text { Yugoslav } \\
\text { Republic of } \\
\text { Macedonia }\end{array}$ & 90 & 98 \\
\hline Latvia & 93 & 99 & Turkey & : & $:$ \\
\hline Lithuania & 100 & 100 & Luxemburg & 98 & 100 \\
\hline
\end{tabular}

Source: Eurostat,

http://appsso.eurostat.ec.europa.eu/nui/show.do?dataset=isoc_ci_in_en2\&lang=en

* Small enterprises (10-49 employees), without financial sector

** Large enterprises (250 employees or more), without financial sector

The differentiation in the Internet usage depending on the size of the enterprise is verified by Table 8 too, where the percentage of large enterprises (over 250 employees) is shown in more advanced internet applications, thus the possibility to employ long-distance employees who are connected with the enterprise's computer systems from home (2006). On the contrary, for small enterprises the long-term employed staff decreases. Thus, the differences in the development of the enterprises remain against the small ones and in favor of the large ones.

It is important to mention that apart from the differences that prevail between the size of the enterprises; the differences between the European Union countries are also visible. The highest percentages of employing long-distance employees who are connected via informatics systems from home are mainly presented in the Northern - Western Countries in comparison with the respective Southern, Central - Eastern countries., as do not only in the large enterprises of these countries, that prevail with percentages that are often over $70 \%$ [Denmark (95\%), Finland (77\%), Sweden (84\%), United Kingdom (79\%), Iceland (66\%), Norway (94\%), Belgium (71\%), Ireland (59\%), the Netherlands (85\%)] as well as the small ones [Denmark (46\%), Finland (24\%), Sweden (34\%), United Kingdom (26\%), Iceland (42\%), Norway (44\%), Belgium (21\%), Ireland (20\%), the Netherlands (29\%)] but in the smaller enterprises as well. 
Table 8: Percentage \% of enterprises that have long-distance employees who are connected with the enterprise's computer systems from home (2006)

\begin{tabular}{|c|c|c|c|}
\hline & $\begin{array}{c}\text { Small } \\
\text { enterprises* }\end{array}$ & $\begin{array}{c}\text { Medium } \\
\text { enterprises }\end{array}$ & $\begin{array}{c}\text { Large } \\
\text { enterprises }^{* * *} \\
\end{array}$ \\
\hline EU ( 27 countries) & 13 & 30 & 55 \\
\hline Belgium & 21 & 50 & 71 \\
\hline Bulgaria & 9 & 10 & 17 \\
\hline Czech Republic & 15 & 31 & 48 \\
\hline Denmark & 46 & 81 & 95 \\
\hline Germany & 15 & 39 & 65 \\
\hline Estonia & 18 & 34 & 53 \\
\hline Ireland & 20 & 38 & 59 \\
\hline Greece & 14 & 25 & 52 \\
\hline Spain & 5 & 17 & 40 \\
\hline Italy & 2 & 7 & 23 \\
\hline Cyprus & 10 & 28 & 62 \\
\hline Latvia & 5 & 12 & 27 \\
\hline Lithuania & 11 & 13 & 30 \\
\hline Luxemburg & 16 & 25 & 66 \\
\hline Hungary & 8 & 16 & 36 \\
\hline Malta & $:$ & $:$ & : \\
\hline The Netherlands & 29 & 56 & 85 \\
\hline Austria & 16 & 37 & 64 \\
\hline Poland & 3 & 8 & 15 \\
\hline Portugal & 7 & 21 & 49 \\
\hline Romania & 6 & 9 & 20 \\
\hline Slovenia & 23 & 32 & 65 \\
\hline Slovakia & 12 & 17 & 34 \\
\hline Finland & 24 & 56 & 77 \\
\hline Sweden & 34 & 59 & 84 \\
\hline United Kingdom & 26 & 49 & 79 \\
\hline Iceland & 42 & 67 & 66 \\
\hline Norway & 44 & 78 & 94 \\
\hline
\end{tabular}

Source: Eurostat,

http://epp.eurostat.ec.europa.eu/tgm/refreshTableAction.do?tab=table\&plugin=1\&pcode=tin00082\&language=en

* Small enterprises (10-49 employees), without the financial sector

** Medium enterprises (50-249 employees), without the financial sector

*** Large enterprises ( 250 employees or more), without the financial sector

\section{CONCLUSION}

On the basis of the theoretical documentation where the questions were raised that approach the dynamic of differentiated characteristics that highlight new forms of inequalities in various levels - and in particular between countries, on a different financial level and educational capital, reaching even enterprises with different sizes, the following conclusions derive, based on the analysis that preceded:

By giving the usage variable a content, thus by detecting its qualitative characteristics on the expected utility through obtaining valuable information, upgrading skills and learning outcomes, the finding is fierce that on a level of people the differentiation regarding the usage 
and the way of usage is correlated with the intensity of social inequalities and mainly with the new features the inequalities which are connected to the utilization of new technologies present. Those differentiations, as they have been commented on through the tables that have been presented, reflect common characteristics of citizens regarding the qualitative and productive utilization of modern communication media that are obviously differentiated on a geographical level, depending on the progress, the achievements and the integration grade of modern means of information and communication and the facilitation the various member states provide to the citizens within the unified European area to utilize those possibilities that are being provided.

So, it is ascertained that citizens of countries, that have modern means of information and communication with advanced possibilities of utilization, such as the Northern Western European countries, indeed utilize those possibilities in very high percentages. This facilitation is the result of the development perspectives that those member states have drawn on a level of political integration of new technologies in the sector of finances, work and promotion of the entrepreneurial spirit.

The finding, that the possibilities that are provided are utilized on a high level in those countries and with relatively small internal differentiations from citizens who present different financial characteristics, a different educational level and social capital, is also important. It is typical, that all chances of utilizing digital means are diffused in all educational and income levels, something that is interpreted from the fact that even people with a low level of education or income are not excluded from information society and, by extension they do not face or experience the special type of social inequalities regarding the criterion of penetration and utilization the modern media offer very strongly. This ascertainment clearly shows elements of digital convergence and internal social cohesion in these countries.

On the other hand and on a level of unified European area the intended convergence is reversed, given that in the European South the internal differentiations are large and are ascertained by the width of deviation presented by the different socio-economic groups regarding the utilization of the possibilities of using new technologies. So, the digital divide is obvious in the internal of those countries (of the European South), as well as in an overall comparison of the European countries on a geographical North-South level.

Those differentiations in combination with the growth of the divide as well as with the inability to monitor and utilize the possibilities and goods by large population strata, not only solidify social inequalities, but there is also a risk emerging that those inequalities will broaden. It concerns inequalities that obtain new characteristics and are largely connected with the inability of structural changes and political measures that will encourage the use of new technologies to predominate, which may be not only individually but overall efficient as well, to the extent that it either follows a central or peripheral planning of confirmation or validation, or there is a recognition of the success in the framework of entrepreneurship and innovation.

Furthermore, the finding that the simple dissemination of usage in not capable to reverse this evolution is also important, because the main criterion of an eventual reversal is the reinforcement of the qualitative characteristics of usage and in particular those that are connected to the professional perspective, the entrepreneurial spirit and innovation, something that is not yet apparent as a possible evolution for a large number of citizens. At this point it has to be mentioned that the success of a broad dissemination, which however is reduced to the usage in the framework of free time and recreation, cannot bring upon a reversal in this situation. 
On another level that refers to the differentiations regarding the use of new technologies concerning enterprises, no strong deviations are reflected given that the usage is widespread enough in all the forms of enterprises. Of course, differences are also presented here that are mainly detected in the innovation and acceleration of entrepreneurial activity in an international environment, something that requires an even higher utilization of modern technological means on the part of certain enterprises. Furthermore, regarding enterprises the differentiation especially regards special cost-saving usages which also facilitate social problems (reconciliation of family and work), such as teleworking. Here, the precedence of the already privileged large enterprises, which due to the allocation of resources and integration of innovation differentiate themselves even more from the small enterprises regarding the prospects for development, can be seen.

In conclusion and on a level of social inequalities, the weaker socio-economic groups still fall quantitatively and qualitatively short in Internet usage, a fact that means high social inequalities. The divide is more intense in the countries in the South compared to the countries in the North and West, so that not only shortage can be noticed in the former in comparison with the latter, but regression of the aspired social cohesion too, which endangers social peace and the prospects of development and social justice.

\section{References}

Bucy, E. P., Social access to the internet, Harvard International Journal of Press/Politics, 2000, 5(1), 50-61.

Mancinelli, E., E-inclusion in Information Society, In Pinter, R. (edit.), Information Society, Thessaloniki:

Technological Educational Institute of Thessaloniki, 2008, p. 247-270.

Peter, J., \& Valkenburg, P. M., Adolescents' internet use: Testing the “disappearing digital divide” versus the “emerging digital differentiation” approach. Poetics, 2006, 34: p. 293-305.

Castells, M., The Rise Of The Network Society, Oxford: Blackwell Publishers, 2000.

Van Dijk, J., The Deepening Divide: Inequality in the Information Society, Thousand Oaks CA, London, New Delhi: Sage Publications, 2005.

DiMaggio, P., Hargittai, E., Russell Numan, W., \& Robinson, J. P., Social Implications of the Internet, Annual Review of Sociology, 2001: 27:"307-336.

Witte, J. C., \& Mannon, S. E., The Internet and Social Inequalities, New York: Routledge, 2010.

Bonfadelli, H., The Internet and knowledge gaps, A theoretical and empirical investigation, European Journal of Communication, 2002: 17(1), 65-84. 